\title{
Anti-inflammatory, Anxiolytic and Antioxidant Property of Lactuca sativa $L$ and Formulation of Microspheres Loaded Sustained Release Anti-inflammatory Gel
}

\author{
Rajendra Gyawali*1, Anupama Ghimireㄹ, Apeksha Khatiwada1, Prakshit Niraula1, \\ Ushma Sharma ${ }^{1}$, Roshani Thapa ${ }^{1}$ \\ ${ }^{1}$ Department of Pharmacy, Kathmandu University, Dhulikhel, Kavre, Nepal \\ *Corresponding E-mail:ragyawali@gmail.com
}

(Received: March 15, 2020; Revised: April 1, 2020 \& Accepted: May 25, 2020)

\begin{abstract}
Anti-inflammatory and anxiolytic properties of Lactuca sativa L extract was evaluated by formalin induced mice paw edema test, and elevated plus maze animal model respectively. Solid microspheres containing dispersed extract were obtained by water-in-oil-in-water multiple emulsion system followed by solvent evaporation method. Optimization was carried out using Minitab 16 and optimized microspheres were loaded into a gel base. Anti-oxidant activity of optimized microspheres loaded gel was evaluated using DPPH (2,2-diphenyl1-picrylhydrazyl) assay. The gel was also evaluated for its physical properties, drug release kinetics and antiinflammatory activity using formalin induced mice-paw edema test where the anti-inflammatory potential was compared to marketed diclofenac gel $(1.16 \% \mathrm{w} / \mathrm{w})$. All doses of extract as well as microsphere loaded sustained release anti-inflammatory gel showed a dose and time dependent inhibition of edema $(\mathrm{P}<0.05)$, the extract also showed a dose dependent inhibition of level of anxiety $(\mathrm{P}<0.001)$. Potential anti-oxidant activity was seen with different concentration of crude extract and microsphere loaded gel. The anti-oxidant potential was compared using $\mathrm{IC}_{50}$ value which was $5.62 \mu \mathrm{g} / \mathrm{mL}, 6.34 \mu \mathrm{g} / \mathrm{mL}, 8.25 \mu \mathrm{g} / \mathrm{mL}$ for ascorbic acid, methanolic extract of L. sativa and microspheres loaded gel respectively.
\end{abstract}

Keywords: Lactuca sativa L, anti-inflammatory and anxiolytic activity, antioxidant, microspheres, sustained release gel

\section{Introduction}

Inflammation is a normal biological process in response to tissue injury, microbial pathogen infection, and chemical irritation. Inflammation is initiated by migration of immune cells from blood vessels and release of mediators at the site of damage. This process is followed by recruitment of inflammatory cells, release of ROS, RNS, and pro-inflammatory cytokines to eliminate foreign pathogens, and repairing injured tissues. In general, normal inflammation is rapid and self-limiting, but aberrant resolution and prolonged inflammation cause various chronic disorders [1]. The unique antioxidant combinations could be used therapeutically to reduce the inflammatory response and stimulate the immune system. Mechanisms of antioxidant action can include; suppression of ROS formation either by inhibition of enzymes or by chelating trace elements involved in free radical generation; scavenging ROS; and upregulation or protection of antioxidant defenses. Anxiety disorders may be caused by problems in the functioning of brain circuits that regulate fear and other emotions. Moreover, certain environmental factors such as a trauma or significant event may trigger an anxiety disorder in people who have an inherited susceptibility to developing the disorder [24]. Oxidative stress and inflammation are the basis of many chronic diseases.

Lactuca sativa L is a leafy vegetable, an annual plant with basal rosette leaves. It requires relatively low temperature to prevent from flowering quickly. Its extracts are used in the skin cream and lotions to 
treat the sunburn and rough skin and are also thought to be beneficial in liver issues. It possesses sedative, anticonvulsant, anxiolytic, analgesic, hypoglycemic and antifungal, anticancer properties. It was also demonstrated that it possesses antioxidant, antiinflammatory and laxative property [5].

Microspheres are monolithic sphere or therapeutic agent distributed throughout the matrix either as a molecular dispersion of particles. Microspheres provide constant and prolonged therapeutic effect, which will reduce the dosing frequency and thereby improve the patient compliance. Better drug utilization will improve the bioavailability and reduce the incidence or intensity of adverse effects. Microsphere morphology allows a controllable variability in degradation and drug release [6].

Plant derived phytochemicals and extracts have recently attracted the great interest towards their applications in health care system. The development of herbal formulations into suitable doses form and evaluating the pharmaceutical parameters are utmost important for scientific assurance of such traditional applications and public acceptance of these herbs. The medicinal plants described in the present investigation have been selected on the basis of its traditional applications in Nepal. To promote the use of Nepalese medicinal plants as potential sources of skin care products, it is important to thoroughly find out their phytochemical profile, bioactive properties, design suitable formulation. Taking these precedents into consideration, the objective of the present study was to formulate and evaluate the pharmacological properties of extract and formulate the antiinflammatory gel.

\section{Materials and Methods}

\section{Plant material}

Lactuca sativa L (Asteraceae family) leaves were collected from local agricultural farm at Kathmandu valley, Nepal and identified by Botanist Tirtha Maiya Shrestha, visiting faculty of Department of Pharmacy, Kathmandu University, Nepal. The air dried ground (mesh 80 ) plant material was soaked in $90 \%$ ethanol in conical flask for $48 \mathrm{~h}$. The extract was separated from the residues by filtering through Whatman no. 1 filter paper. The extraction procedure was carried out twice with sample. Thus, the extraction was completed in two weeks. The combined extracts were dried at 40 ${ }^{0} \mathrm{C}$ using a rotary evaporator. The dried crude extracts were weighted to calculate the yield and stored in refrigerator $\left(-4{ }^{\circ} \mathrm{C}\right)$ until used for analyses.

\section{Animals}

The Swiss albino mice were purchased from Okharpauwa Animal Farm, Tripureshwar, Kathmandu. The mice were kept in animal house of University before the experiment but transferred in polypropylene cages with free access to diet and water.

\section{Preliminary phytochemical screening}

Preliminary screening for the presence of alkaloids, tannins, polyphenols, reducing sugar, coumarins, saponins, anthraquinone glycoside and flavones by the reported protocol [7].

\section{Anti-inflammatory activity}

For the evaluation of anti-inflammatory activity of gel, total of 20 Swiss albino male mice of average weight $25 \mathrm{~g}$ were placed into cages and grouped into four (A-D) consisting five mice in each group. Diclofenac gel $(1.16 \% \mathrm{w} / \mathrm{w})$ was applied to group A mice on the inflamed area, $2 \%$ and $4 \%$ optimized microsphere loaded gel to group B and C respectively. Group D was used as control and therefore carbopol base was applied to the inflamed area. Paw volume was measured plethysmometrically before standard and extract administration and 30 minutes post administration of doses for 2 hours. Level of inflammation was calculated and data were statistically analyzed [8].

\section{Anxiolytic activity}

The anxiolytic activity was examined by using the Elevated Plus Maze apparatus. A total of 20 Swiss albino male mice of average weight $25 \mathrm{~g}$ were used. They were placed into cages and grouped into four (A-D) consisting five mice in each group. The animals were deprived of feed for 12 hours prior to experiment and were allowed access to pure drinking water. Individual oral dosage $0.25 \mathrm{~mL}$ of diazepam $2 \mathrm{mg} / \mathrm{kg}$ to group A, test dose $200 \mathrm{mg} / \mathrm{kg}$ extract to group B and test dose $400 \mathrm{mg} / \mathrm{kg}$ to group C and group D was used as control i.e. distilled water was given orally. After 60 minutes, each of them was placed in elevated 
plus maze apparatus consisting open arm and closed arm. The entry in open arm and closed arm were noted and compared. The residence time in respective arm and relative preference to open arm was analyzed to determine anxiolytic potential of doses [9].

\section{Microspheres development and formulation of microsphere loaded gel}

Ethyl cellulose was dissolved in 1:1 solution of acetonitrile and chloroform. Aqueous drug solution was added drop wise using high-speed magnetic stirrer operating around $900 \mathrm{rpm}$ for about 10 minutes to prepare w/o primary emulsion. Primary emulsion was then subjected to probe sonication for given time interval and then added to external phase containing surfactant (tween 80) at magnetic stirrer speed around $900 \mathrm{rpm}$ for 10 minutes and then again probe sonication was done for the same time interval. It was finally stirred at $900 \mathrm{rpm}$ for 2 hours at room temperature for evaporation of organic solvent. Obtained microspheres were collected by filtration and then dried in hot air oven for 15 minutes and stored in desicator at ambient temperature until further evaluation [10]. Microspheres were evaluated for physical parameters including particle size and entrapment efficiency. Particle size analysis was done using trinocular stereo zoom microscope and the images were analyzed for spherical surface morphology and size was noted with the help of graduated scale on the slide. The drug content of microsphere was determined spectrophotometrically $(\lambda \max =281 \mathrm{~nm})$. A sample of microsphere $(10 \mathrm{mg})$ was dissolved in $10 \mathrm{~mL}$ of phosphate buffer ( $\mathrm{pH}$ 6.8) and kept overnight. The drug content in microspheres was calculated according to following formula:

$$
\text { Entrapment efficiency }=\frac{\begin{array}{c}
\text { Actual drug content } \\
\text { in microsphere }
\end{array}}{\text { Theoretical drug content }} \times 100 \%
$$

Optimization was carried out depending on Boxbehnken design via Minitab software and the optimized microspheres were dispersed in 1\% carbopol gel base.

\section{Evaluation of microsphere loaded topical gel}

The gel was evaluated for its $\mathrm{pH}$, viscosity, skin irritation test, clarity and appearance, spreadability and extrudability. Modified Franz diffusion cell was used for ex-vivo permeation study. Skin of goat was used for the skin permeation study. The skin was mounted in modified Franz diffusion cell and known quantity ( $1 \mathrm{~g}$ gel containing $100 \mathrm{mg}$ of drug) was spread uniformly on the skin on donor side. $\mathrm{pH} 6.8$ phosphate buffer was used as the acceptor medium, from which samples were collected at regular interval drug 12 hour and replaced with same amount of buffer to maintain the receptor phase volume. Absorbance was measured at $281 \mathrm{~nm}$ using UV-spectrophotometer and the $\%$ drug release was calculated using following equation:

$\begin{aligned} & \text { Drug release } \\ & \text { percentage }\end{aligned}=\frac{\text { Conc. }(\mathrm{mg} / \mathrm{mL}) \times 50(\mathrm{~mL}) \times \text { Dilution factor }}{\text { Drug content in microspheres }(\mathrm{mg})} \times 100 \%$

In-vitro release profile of gel was studied by dissolution apparatus USP XXIII (paddle type). Cellophane membrane was used and weighed quantity of gel containing $100 \mathrm{mg}$ of drug was introduced in the membrane and clipped on both sides. This was then dipped in basket containing $6.8 \mathrm{pH}$ buffer as dissolution medium. The speed of the rotation was $50 \mathrm{rpm}$ and temperature was maintained at $37 \pm 0.5$ ${ }^{\circ} \mathrm{C}$.sample aliquots were withdrawn from dissolution medium at predetermined time intervals and were analyzed by UV spectrophotometer at $281 \mathrm{~nm}$. The drug release percentage was calculated as:

$\begin{aligned} & \text { Drug release } \\ & \text { percentage }\end{aligned}=\frac{\text { Conc. }(\mathrm{mg} / \mathrm{mL}) \times 900(\mathrm{~mL}) \times \text { Dilution factor }}{\text { Drug content in microspheres }(\mathrm{mg})} \times 100 \%$

\section{Antioxidant activity}

The scavenging activity of sample for DPPH was monitored according to method of Yen [11]. Briefly a $1 \mathrm{~mL}$ of aliquot test sample was added to $1 \mathrm{~mL}$ of $0.1 \mathrm{mM}$ DPPH methanolic solution. The mixture was vortexed for 1 minutes and left to stand at room temperature and absorbance was read at $517 \mathrm{~nm}$. The ability to scavenge DPPH radical was calculated using formula:

$$
\text { Percentage scavenging }=\frac{A_{0}-A_{1}}{A_{0}} \times 100
$$

Where, $A_{0}=$ Absorbance of DPPH solution $A_{t}=$ Absorbance of DPPH along with different concentration of microsphere loaded gel and crude extracts $(1 \mu \mathrm{g} / \mathrm{mL}, 2$ $\mu \mathrm{g} / \mathrm{mL}, 3 \mu \mathrm{g} / \mathrm{mL}, 4 \mu \mathrm{g} / \mathrm{mL}, 5 \mu \mathrm{g} / \mathrm{L}, 10 \mu \mathrm{g} / \mathrm{mL})$

$\mathrm{IC}_{50}$ (Inhibitory concentration) was calculated from equation of line obtained by plotting a graph of concentration versus \% scavenging of DPPH. 


\section{Statistical analysis}

All experiment results were analyzed and expressed statistically by Dunnet's multiple comparison test and analysis of variance (ANOVA).

\section{Results and Discussion}

\section{Anti-inflammatory activity}

The effect of extract of L. sativa L (400 mg/kg) on paw edema showed that it has maximum inhibitory effect during second phase and showed its effect after half an hour after the injection of formalin with good anti-inflammatory property $(\mathrm{P}<0.05)$ in dose dependent pattern (Table 1). Indomethacin showed its significant inhibitory action towards early phase also. The extract $(200 \mathrm{mg} / \mathrm{kg})$ showed its inhibitory action towards the later phase and maintained up to 5 hours, which might be due to inhibition of prostaglandinmediated inflammation.

\section{Evaluation and optimization of microspheres}

Box-Behnken of three factors in three level namely amount of polymer, probe sonication time and surfactant concentration was performed using Minitab 16 in response to encapsulation efficiency and particle size.

The independent parameters selected for optimization were concentration of surfactant, amount of polymer and sonication time. The dependent parameters were entrapment efficiency and particle size. Thus formed microspheres prepared from solvent evaporation method were solid, spherical and greenish in color. The results obtained during evaluation of particle size and entrapment efficiency showed that it is higher when the particle size is also big.

The counter plot indicates that with the increase in amount of polymer the particle size also increased and with increase in sonication time particle size

Table 1: Various sizes of edema expressed ad Mean $\pm S D v s$. doses of standard and extract

\begin{tabular}{|c|c|c|c|c|c|c|c|}
\hline Group & $0 \min$ & $30 \mathrm{~min}$ & $60 \mathrm{~min}$ & $120 \mathrm{~min}$ & $180 \mathrm{~min}$ & $240 \mathrm{~min}$ & $300 \mathrm{~min}$ \\
\hline Control & $0.226 \pm 0.02$ & $0.274 \pm 0.019$ & $0.336 \pm 0.011$ & $0.374 \pm 0.011$ & $0.394 \pm 0.011$ & $0.428 \pm 0.013$ & $0.464 \pm 0.017$ \\
\hline $\begin{array}{l}\text { Standard } \\
\text { (indomethacin) }\end{array}$ & $0.256 \pm 0.026$ & $0.274 \pm 0.011$ & $0.294 \pm 0.019$ & $0.332 \pm 0.013$ & $0.354 \pm 0.024$ & $0.378 \pm 0.008$ & $0.394 \pm 0.011$ \\
\hline $\begin{array}{l}\text { Test } 1 \\
(200 \mathrm{mg} / \mathrm{kg})\end{array}$ & $0.24 \pm 0.016$ & $0.276 \pm 0.013$ & $0.314 \pm 0.011$ & $0.33 \pm 0.007$ & $0.358 \pm 0.0008$ & $0.37 \pm 0.007$ & $0.384 \pm 0.013$ \\
\hline $\begin{array}{l}\text { Test } 2 \\
(400 \mathrm{mg} / \mathrm{kg})\end{array}$ & $0.234 \pm 0.0009$ & $0.25 \pm 0.07$ & $0.278 \pm 0.008$ & $0.292 \pm 0.008$ & $0.316 \pm 0.0089$ & $0.332 \pm 0.008$ & $0.356 \pm 0.013$ \\
\hline
\end{tabular}

\section{Anti-anxiety activity}

Extract at doses 200 and $400 \mathrm{mg} / \mathrm{kg} \quad(\mathrm{P}<0.001)$ very significantly increased the number of entry and time in the open arm with decrease in closed arm when compared to the control treated group (Figure 1). In elevated plus maze mice normally prefers closed arm but this preference appears to reflect an aversion towards open arm generated by fear of open spaces.

Table 2: Time spent in open arm by control vs. standard and test samples

\begin{tabular}{lll}
\hline Group & $\begin{array}{l}\text { Time spent in } \\
\text { open } \operatorname{arm}(\mathbf{m i n})\end{array}$ & $\begin{array}{l}\text { Inhibition } \\
\mathbf{( \% )}\end{array}$ \\
\hline Control & $3.2160 \pm 1.2687$ & 0.0 \\
Standard & $6.916 \pm 0.9386$ & 109 \\
Test A & $7.3 \pm 0.97$ & 127 \\
Test B & $7.78 \pm 0.8578$ & 141 \\
\hline
\end{tabular}

Table 3: Box Behnken design for formulation of microspheres

\begin{tabular}{cccc}
\hline $\begin{array}{c}\text { Batch } \\
\text { no. }\end{array}$ & $\begin{array}{c}\text { Amount of } \\
\text { polymer } \\
\text { (mg) }\end{array}$ & $\begin{array}{c}\text { Sonication } \\
\text { time (sec) }\end{array}$ & $\begin{array}{c}\text { Surfactant } \\
\text { Conc.(\%) }\end{array}$ \\
\hline ML1 & 175 & 20 & 1.5 \\
ML2 & 250 & 10 & 1.5 \\
ML3 & 175 & 20 & 1.5 \\
ML4 & 175 & 20 & 1.5 \\
ML5 & 250 & 20 & 0.5 \\
ML6 & 100 & 30 & 1.5 \\
ML7 & 175 & 10 & 2.5 \\
ML8 & 175 & 30 & 2.5 \\
ML9 & 250 & 30 & 1.5 \\
ML10 & 100 & 10 & 1.5 \\
ML11 & 250 & 20 & 2.5 \\
ML12 & 100 & 20 & 0.5 \\
ML13 & 100 & 20 & 2.5 \\
ML14 & 175 & 10 & 0.5 \\
ML15 & 175 & 30 & 0.5 \\
\hline
\end{tabular}


decreased (Fig 1). The $\mathrm{P}$ value $<0.05$ was obtained for polymer, surfactant polymer interaction and surfactant concentration which indicates that these parameters significantly affect the particle size.

Counter plot showing that entrapment efficiency is higher i.e. $>70 \%$ when the polymer concentration is high and it also increases with increase in surfactant concentration but this is possible only at definite

\section{Contour plots of particle size}
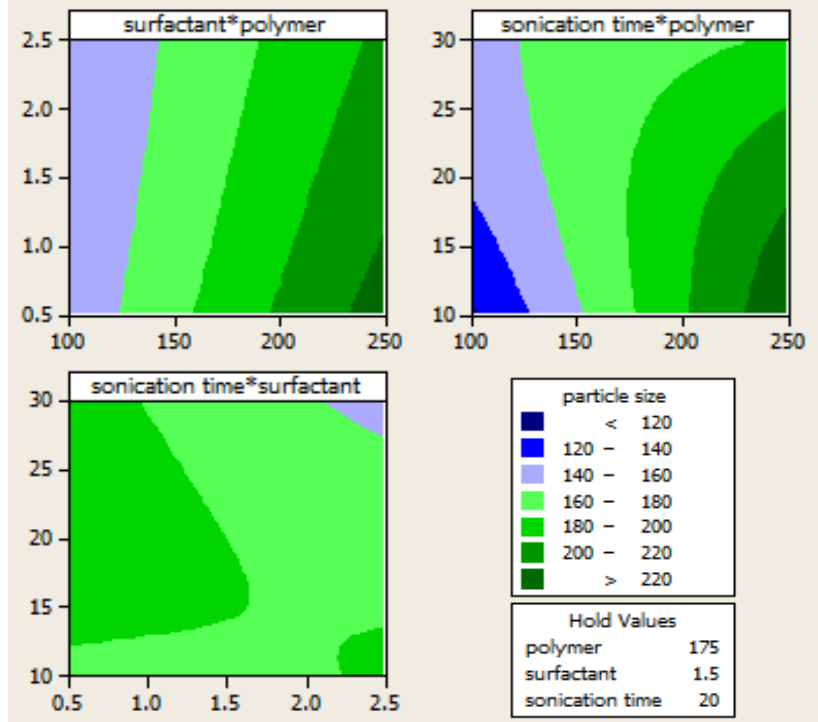

Figure 1: Effects of surfactant concentration, amount of polymer and sonication time on particle size

Contour plots of entrapment efficiency

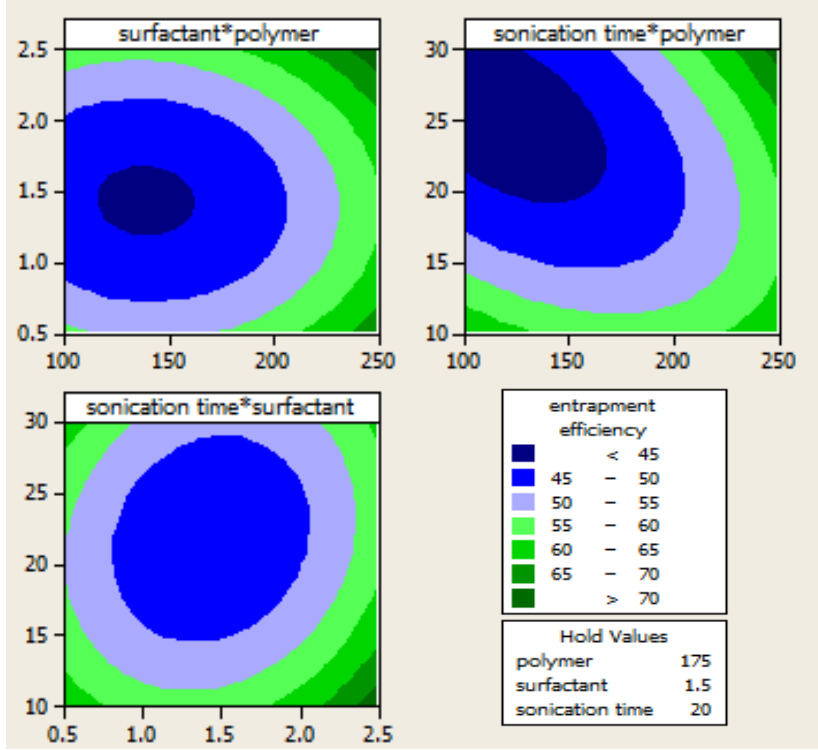

Figure 2: Effects of surfactant, polymer and sonication time on entrapment efficiency amount of drug (Fig 2). The p value $<0.05$ is obtained for polymer polymer interaction, surfactant surfactant interaction, surfactant polymer interaction and surfactant sonication time interaction. This suggests that above mentioned interactions significantly affect the entrapment efficiencies. Higher entrapment efficiency was observed with high surfactant concentration and high polymer. It was also seen in case of high surfactant and low sonication time.

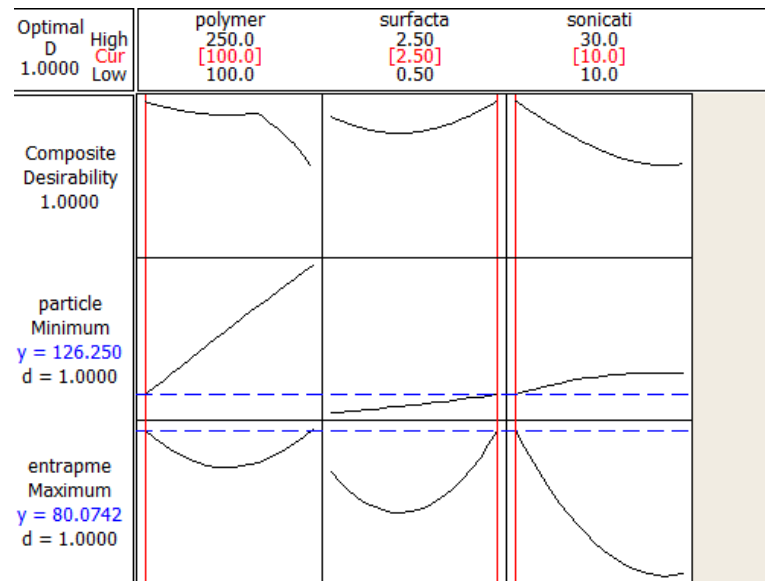

Figure 3: Optimization plot of microsphere

Depending upon the optimization plot the microspheres were developed with particle size 140 $\mu \mathrm{m}$. Since the desired particle size was not obtained therefore microspheres were developed by slightly increasing the sonication time and keeping all other parameters constant. Finally the microsphere with nearly optimum size was obtained i.e. $120 \mu \mathrm{m}$. Entrapment efficiency was calculated as follow:

Entrapment efficiency $=\frac{\text { Observed concentration }}{\text { Theoretical concentration }} \times 100 \%$

$$
\begin{aligned}
& =\frac{0.2585}{0.33} \times 100 \% \\
& =78.35 \%
\end{aligned}
$$

\section{Drug release kinetics}

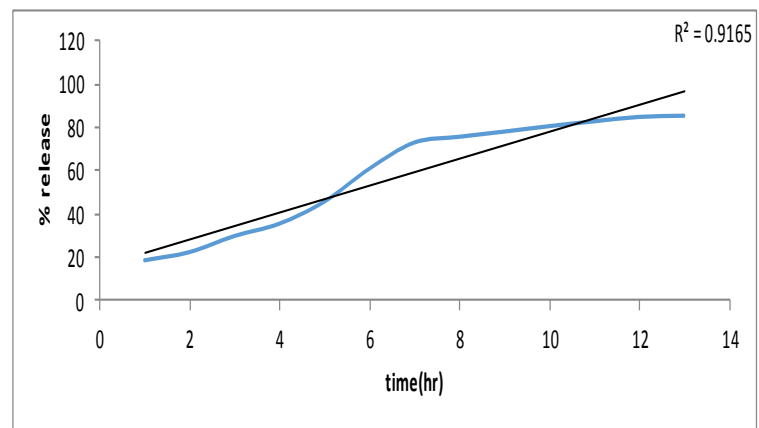

Figure 4: Zero-order release profile of optimized microsphere loaded gel 


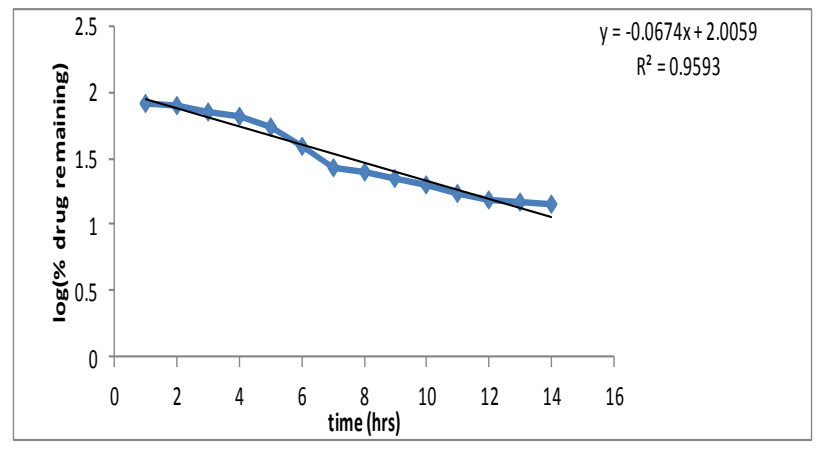

Figure 5: First-order release profile of optimized microsphere loaded gel

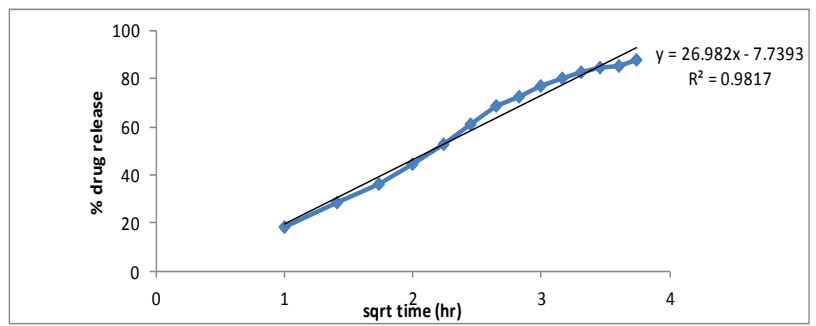

Figure 6: Higuchi model release profile of optimized microsphere loaded gel

From the $\mathrm{R}^{2}$ values obtained in different mathematical model, we conclude that optimized microsphere loaded formulation correlates with Higuchi model. Therefore the formulation follows Higuchi model release.

\section{Drug release behavior of crude extract and optimized microsphere-loaded gel}

a)The release profile of the crude extract was tested by loading the weighed amount of extract into cellophane membrane and introducing it to USP dissolution apparatus (Paddle type) at $37 \pm 0.5^{\circ} \mathrm{C}$ and $50 \mathrm{rpm}$ using $900 \mathrm{~mL}$ phosphate buffer $\mathrm{pH} 6.8$ (Fig 7).

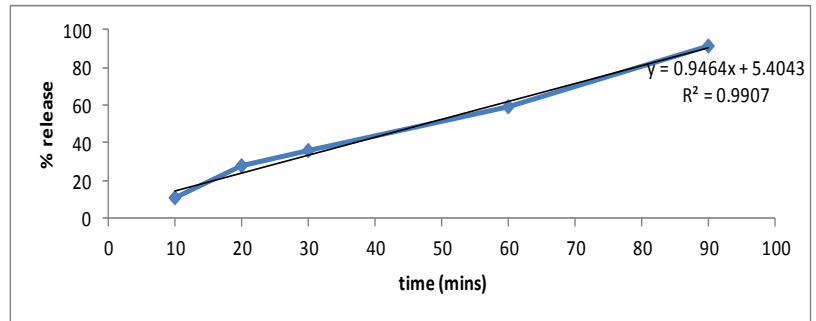

Figure 7: Release profile of crude extract through cellophane membrane

b) The release profile of the formulation was tested by loading the formulation into cellophane membrane and introducing it to USP dissolution apparatus
(Paddle type) at $37 \pm 0.5{ }^{\circ} \mathrm{C}$ and $50 \mathrm{rpm}$ using $900 \mathrm{~mL}$ phosphate buffer pH 6.8 (Fig 8 and 9).

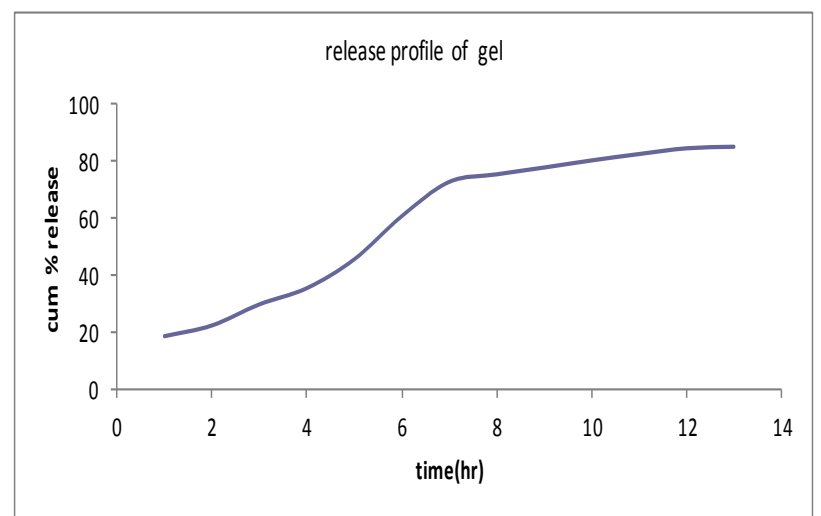

Figure 8: Drug release profile of microsphere loaded gel through cellophane membrane

\section{release profile of $2 \% \mathrm{gel}$}

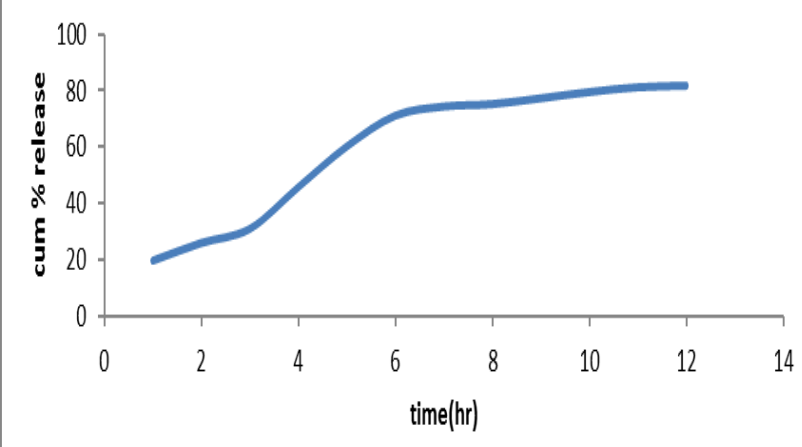

Figure 9: Drug release profile of microsphere loaded gel through gat skin

\section{Antioxidant activity}

Anti-oxidant activity of crude extract and microsphereloaded gel was calculated using $\mathrm{IC}_{50}$ value. The $\mathrm{IC}_{50}$ value of reference standard ascorbic acid in methanol was found to be $5.62 \mu \mathrm{g} / \mathrm{mL}$. Methanolic extract of L. sativa $\mathrm{L}$ and optimized microsphere (developed from $L$. sativa $L$ extract) loaded gel showed effective antioxidant activity with $\mathrm{IC}_{50}$ value of $6.34 \mu \mathrm{g} / \mathrm{mL}$ and $8.25 \mu \mathrm{g} / \mathrm{mL}$. This study revealed that $L$. sativa $\mathrm{L}$ crude extract as well as formulation possess significant anti-oxidant activity and this may be due to presence of various bioactive component present in the plant, which was evaluated during phytochemical screening. 


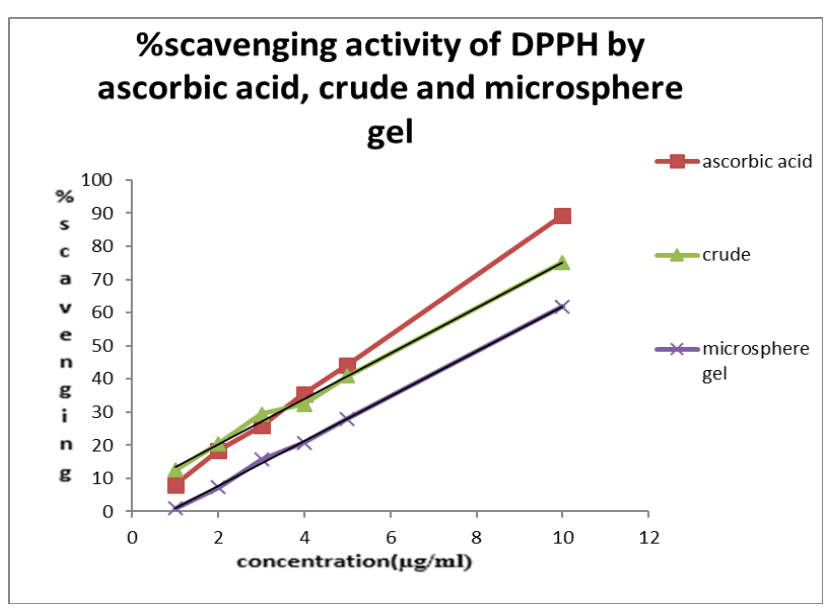

Figure 10: Antioxidant activity of crude extract and optimized microsphere loaded gel

\section{Anti-inflammatory activity of optimized microsphere loaded gel}

The significant inhibitory activity shown by the extract of L. sativa L (200 and $400 \mathrm{mg} / \mathrm{kg}$ ) over a period of $6 \mathrm{~h}$ in formalin-induced inflammation was quite similar to that exhibited by the group treated with diclofenac diethylamine (Table 4). This shows the formulation has potential anti-inflammatory action $(\mathrm{P}<0.05)$. These results indicate that the formulation acts in later phases in dose dependent manner, probably involving arachidonic acid metabolites, which produce an edema dependent on neutrophils mobilization. The early phase (1-2 h) of the model is mainly mediated by histamine, serotonin and increased synthesis of prostaglandins in the damaged tissue surroundings. The late phase is sustained by prostaglandin release and mediated by bradykinin, leukotrienes, polymorphonuclear cells and prostaglandins produced by tissue macrophages.
This anti-inflammatory effect of the extract observed might be due to the presence of flavonoids in the plant [14].

There has been an increasing amount of drug discovery and drug formulations development from natural compounds in the past days, which can be attributed to development of modern technologies [15]. The herbal formulations are now available into various novel drug delivery system like polymeric nanoparticles, nanocapsules, liposomes, nanoemulsions etc [16]. The use of novel formulations like microsphere can overcome the limitation of conventional formulations like solubility, bioavailability, toxicity and confer advantages like increased stability, pharmacological activity, tissue macrophages distribution and patient compliance. It can further help for the targeted delivery of drugs to desired site of action $[16,17]$. Anxiety disorders are the most common psychiatric illnesses in the world. Hydro-alcohol extract of L. sativa rich in polyphenols possess potent anxiolytic property in pervious investigations. The present result showing that, L. sativa includes anti-inflammatory action, anxiolytic activity and anti-oxidant activity development of novel herbal formulation which aims to develop L. sativa microsphere and dispersion of optimized microsphere into gel base to produce sustained release anti-inflammatory action. The study also summarizes the method of preparation, characterization of formulation, type of various ingredients, particle size, entrapment efficiency, route of administration, drug-release kinetics, Invitro release studies, ex-vivo permeation studies and evaluation of biological activity in animal model. Thus, L. sativa is found to have potent antiinflammatory, anxiolytic and antioxidant action. The

Table 4: Summary of sizes of oedema at different time vs. doses of L. sativa $L \&$ diclofenac gel

\begin{tabular}{lllllllll}
\hline Group & 0 min & 30 min & 60min & 120min & 180min & 240min & 300min & 360min \\
\hline Control & $0.22 \pm$ & $0.25 \pm$ & $0.326 \pm$ & $0.352 \pm$ & $0.396 \pm$ & $0.42 \pm$ & $0.434 \pm$ & $0.444 \pm$ \\
& 0.0114 & 0.013 & 0.0114 & 0.0148 & 0.0114 & 0.007 & 0.011 & 0.0152 \\
\hline Standard & $0.236 \pm$ & $0.26 \pm$ & $0.276 \pm$ & $0.288 \pm$ & $0.268 \pm$ & $0.256 \pm$ & $0.25 \pm$ & $0.248 \pm$ \\
& 0.021 & 0.021 & 0.024 & 0.013 & 0.021 & 0.082 & 0.012 & 0.014 \\
\hline Test 1 & $0.224 \pm$ & $0.248 \pm$ & $0.27 \pm$ & $0.28 \pm$ & $0.272 \pm$ & $0.26 \pm$ & $0.256 \pm$ & $0.246 \pm$ \\
(2\% gel) & 0.033 & 0.0319 & 0.038 & 0.0418 & 0.042 & 0.043 & 0.042 & 0.0364 \\
\hline Test 2 & $0.232 \pm$ & $0.266 \pm$ & $0.282 \pm$ & $0.286 \pm$ & $0.284 \pm$ & $0.258 \pm$ & $0.248 \pm$ & $0.238 \pm$ \\
$\mathbf{( 4 \% ~ g e l ) ~}$ & 0.039 & 0.033 & 0.117 & 0.037 & 0.040 & 0.044 & 0.038 & 0.039 \\
\hline
\end{tabular}


optimized formulation showed positive result for sustained releases anti-inflammatory action when the study was conducted in animal model $[5,18]$.

In the present study we put in correlation of L. sativa grown in Nepal which was rich in phytochemicals such as cardiac glycoside, reducing sugar, saponin, coumarin and flavone, greatly contribute to enhance the inflammatory based diseases. This hypothesis is also enforced for a great therapeutic potential.

\section{Conclusion}

This study conclusively shows that, glycoside and phenolics enriched extract of Lactuca sativa and its microsphere loaded sustained release gel possesses anti-inflamatory, anxiolytic and anti-oxidant activity.

\section{Acknowledgements}

Research team would like to acknowledge University Grants Commission, Nepal for support during publication of this research.

\section{References}

1. A. K. Mishra, B. K. Singh, and A. K. Pandey, In vitro-antibacterial activity and phytochemical profiles of Cinnamomum tamala (Tejpat) leaf extracts and oil, Reviews in Infection, 1010, 1, 134-139.

2. A. Bystritsky, S. S. Khalsa, M. E. Cameron, and J. Schiffman, Current diagnosis and treatment of anxiety disorders, Pharmacy and Therapeutics, 2013, 38, 30-57.

3. B. Halliwell and J. M. C. Gutteridge, Free Radicals in Biology and Medicine, Oxford University Press, Oxford, UK, 1998.

4. S. D. Norrholm, and K. J. Ressler, Genetics of anxiety and trauma-related disorders, Neuroscience, 2009, 164(1), 272-287.

5. A. Ahangarpour, H. Heidari, S. A. Mard. Hashemitabar M, and A. Khodadadi, Progesterone and cilostazol protect mice pancreatic islets from oxidative stress induced by hydrogen peroxide, Iranian Journal of Pharmaceutical Research, 2014, 13, 937-944.

6. J. Q. Del Rosso, Benzoyl peroxide microsphere formulation: What is the science supporting microsphere vehicle technology and clinical use?, Journal of Clinical and Aesthetic Dermatology, 2009, 2(9), 46-54.
7. G. E. Trease, and W. C. Evans, Textbook of Pharmacognosy, 12 ${ }^{\text {th }}$ Ed., London: Bailliere Tindall, 1983.

8. M. Sayyah, N. Hadidi, and M. Kamalinejad, Analgesic and anti-inflammatory properties of Lactuca sativa in mice, Ethnophasm, 2004, 92, 325-329.

9. S. N. Harsha, and K. R. Anilakumar, Anxiolytic property of Lactuca sativa, effects on anxiety behaviour induced by novel food and height, Asian Pacefic Journal of Tropical Medicine, 2013, 6, 532-536.

10. S. Tiwari and P. Verma, Microencapsulation technique by solvent evaporation method, International Journal of Pharmacy \& Life Sciences, 2011, 2(8), 998-1005.

11. G. C.Yen, and H. Y. Chen, Antioxidant activity of various tea extract in relation to their antimutagenicity, Journal of Agricultural and Food Chemistry, 1995, 43, 27-37.

12.C. A. Winter, E. A. Risley, and W. Nuss, Carrageenan induced edema in hind paw of rats as an assay for anti-inflammatory drugs, Experimental Biology and Medicine, 1962, 111, 44-547.

13. M. Gupta, U. K. Mazumder, P. Gomathi, and V. Thamilselvan, Anti-inflammatory evaluation of leaves of Plumeria acuminate, BMC Complementary and Alternative Medicine, 2006, 6(36), 1472-6882.

14. M. A. Antonio, A. R. Souza Brito, Oral antiinflammatory and anti-ulcerogenic activities of a hydro alcoholic extract and partitioned fractions of Turnera ulmifolia (Turneraceae), Journal of Ethnopharmacology, 1998, 61, 215-228.

15. H. F. Ji, X. J. Li, and H. Y. Zhang, Natural products and drug discovery. EMBO Reports, 2009, 10(3), 194-200.

16. S. Saraf, Applications of novel drug delivery system for herbal formulations, Fitoterapia, 2010, 81(7), 680-689.

17. N. K. Varde, and D. W. Pack, Microspheres for controlled release drug delivery, Expert Opinion on Biological Therapy, 2004, 4(1), 35-51.

18. B. Zekkori, F. Khallouki, A. Bentayeb, S. Fiorito, F. Preziuso, V. A. Taddeo, F. Epifano and S. Genovese, A new phytochemical and anti-oxidant and anti-inflammatory activities of different Lactuca sativa L. var. crispa extracts, Natural Product Communications, 2018,13(9), 1139-1142. 